Journal: Education, Prevention \& Policy, vol. 17, núm. 5, 2010, pp. 544-559.

\title{
Drug use and peer norms among youth in a high-risk drug use neighbourhood in Buenos Aires.
}

Pawlowicz, María Pía, Zunino Singh, Dhan, Rossi, Diana, Touze, Graciela, Wolman, Guido, Bolyard, Melissa, Sandoval, Milagros, Flom, Peter, Mateu Gelabert, Pedro y Friedman, Samuel.

Cita:

Pawlowicz, María Pía, Zunino Singh, Dhan, Rossi, Diana, Touze, Graciela, Wolman, Guido, Bolyard, Melissa, Sandoval, Milagros, Flom, Peter, Mateu Gelabert, Pedro y Friedman, Samuel (2010). Drug use and peer norms among youth in a high-risk drug use neighbourhood in Buenos Aires. Journal: Education, Prevention \& Policy, 17 (5), 544-559.

Dirección estable: https://www.aacademica.org/maria.pia.pawlowicz/18 ARK: https://n2t.net/ark:/13683/pgaP/ozK

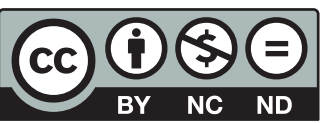




\title{
Drug use and peer norms among youth in a high-risk drug use neighbourhood in Buenos Aires
}

\author{
MARÍA PÍA PAWLOWICZ, DHAN S. ZUNINO SINGH, \\ DIANA ROSSI, GRACIELA TOUZÉ, GUIDO WOLMAN, \\ MELISSA BOLYARD, MILAGROS SANDOVAL, \\ PETER L. FLOM, PEDRO MATEU GELABERT, \\ \& SAMUEL R. FRIEDMAN
}

Intercambios Civil Association, Av. Corrientes $25482^{\circ}$ “D” CP C1046AAP, Buenos Aires, Argentina

\begin{abstract}
Aims: To determine if measures of drug use risk, sexual risk, external norms and internalized norms developed for impoverished neighbourhoods of New York are usable in similar neighbourhoods of Buenos Aires and have similar associations with each other in the two cities despite the many cultural, social, economic and political differences between these localities.

Methods: In 2003-2004, 240 current non-injection drug users (IDUs) and 63 current IDUs, aged 21-35 years, were interviewed in poor neighbourhoods of the Southern Metropolitan Area of Buenos Aires about their drug use, sexual behaviours, internalized norms and external norms (actual and perceived social pressures from others) using measures developed in New York (Flom, Friedman, Benny, \& Curtis, 2001a, Flom, et al., 2001b; Flom, Friedman, Jose, Neaigus, \& Curtis, 2001c). Analyses studied associations between a hierarchical scale of drug use risk and the other variables.

Results: The hierarchical risk scale of drug use was associated with sexual risk behaviours; with external norms towards drug injection and sex with drug injectors, and internalized norms about social distance from drug injectors.

Conclusions: The hierarchical drug use risk scale and the measures of external norms had relationships similar to those found in the earlier studies in New York City. This supports the ideas that these measures may have a degree of cross-cultural applicability.

Correspondence: María Pía Pawlowicz, Intercambios Civil Association, Av. Corrientes $25482^{\circ}$ “D” CP C1046AAP, Buenos Aires, Argentina. Tel: 54114954 7272. Fax: 541149541333. E-mail: investigacion@intercambios.org.ar
\end{abstract}




\section{Introduction}

Psychoactive and/or illicit drug use ('drug use') is a major influence on people's lives. It is often associated with high-risk behaviours and disease. As is true for most of the behaviours, people who engage in drug use tend to be in normative environments that are relatively supportive of these behaviours. The causal processes involved in this have been widely debated with attention paid to norms as shaping behaviours, behaviours as shaping internalized norms through processes of cognitive dissonance and as shaping the norms of friends through behavioural modelling, and to processes of differential association through which people tend to gravitate to peer groups and normative environments that are friendly to their behavioural patterns (differential association processes mean that people gravitate to situations where external norms tend to reinforce their behaviours and internalized norms) (Gorman \& White, 1995; Heckathorn, 1990).

As discussed by Parsons (1951), Heckathorn (1990), Latkin \& Knowlton (2005) and Friedman, Rossi, and Braine (2008), norms can usefully be viewed not as'things' but as processes of interpersonal influence. Actors in the community exert influence on each other; to the extent that such influence is perceived as expressing expected rules of behaviour, the recipients of such influence can be said to be subject to 'external norms;' to the extent they internalize these rules, and they form 'internalized norms.' We have previously described the production of norms in a health-promotion context as intravention' (Friedman, Bolyard, Sandoval, Mateu-Gelabert, \& Neaigus, 2004; Friedman, Bolyard, Maslow, Mateu-Gelabert, \& Sandoval, 2005; Friedman et al., 2007a; Mateu-Gelabert, Friedman \& Sandoval, 2007; Mateu-Gelabert et al., 2008).

Many researchers in these areas view normative processes as reasonably universal in the sense that while the content of the norms and behaviours may vary among subcultures and across societal and cultural regions, the causal relationships among them remain the same.

However, normative processes may vary in different subcultures and also in different cultures and societies. Thus, it becomes problematic - and also important - whether given behaviours such as drug use are related to other behaviours in the same or different ways in different environments and whether behaviours have similar relationships to external norms and to internalized norms in different societies. To study this, it is necessary to find ways to measure behavioural patterns and norms that can be used in different countries.

This article considers these issues in the context of young people and drug use in a largely impoverished community in the southern part of the Buenos Aires metropolitan area. It does this in the form of a partial replication of an earlier similar study conducted in a largely impoverished neighbourhood of New York City. It aims to see how young adults' drug use is associated with their sexual risk behaviours and with their external and internalized norms in these very different social environments. Although both Bushwick (where the previous study was conducted) and Avellaneda, (where the data we focus on here were collected) 
are once-stable industrial areas that have undergone serious deindustrialization, they are in very different societies. Bushwick is an impoverished part of a relatively stable and wealthy country - the United States - that has maintained nondictatorial governmental forms for centuries; and the USA did not undergo largescale social unrest in the period leading up to the study conducted in Bushwick in 1997-2000. Avellaneda, on the other hand, is part of a relatively impoverished country with a culture and national customs that are quite different from those of the USA; and it had a relatively recent experience with a brutal dictatorship (1976-1983) followed by a transition to democratic forms. In addition, in the years leading up to our data collection in 2003-2004, Argentina went through over a decade of worsening unemployment, falling incomes, cut-backs and a currency and banking crisis in the early years of this century that led to mass activism by piqueteros (picketers) from the unemployed in poor communities who blocked roads and took other disruptive actions, seizures of factories and other workplaces by their workers who then ran them as cooperative enterprises, and mass demonstrations in Buenos Aires and other cities that included mass middleclass involvement. This activism led to the ousting of four presidents in a few weeks in the first months of 2002 and was an immediate precursor of this project.

The Bushwick studies alluded to above (Flom et al., 2001a, b, c) were conducted in 1997-2000 and, like the current study, included two samples: a general young adult sample and also a targeted sample of drug-using young adults. This study developed a hierarchical scale of categories of drug use (injection drug users (IDUs); non-IDUs who smoke crack; non-IDus who do not smoke crack but do take cocaine or heroin by non-injected means; cannabis users and non-users) that was adapted for use in the study in Buenos Aires. It also developed methods and questions to study external and internalized peer norms that were used in this study. They found that riskier values on the scale of hierarchical drug use risk were associated with risky sexual behaviour, and also with external norms toward drug use. The Flom et al. studies, however, did not measure internalized norms.

In this article, we discuss ways in which we adapted the scales and items from the New York study for use in Argentina, and then present analyses parallel to those done by the New York team.

\section{Methods}

\section{Population study and data collection}

The study was conducted among young current injecting drug users and other young adults in different neighbourhoods of Avellaneda (Villa Corina, Villa Luján, Dock Sud and Sarandí), in the Southern part of the Buenos Aires Metropolitan Area.

The neighbourhood in which the study was conducted had 329,638 inhabitants in 2001, and was once a highly industrial part of the city. It is now marked by very 
poor living conditions, increased unemployment, a large population of drug users and a high HIV-infection rate, mostly due to injecting drug use (INDEC, 2008).

Questionnaires and sampling procedures were developed for two categories of participants between the ages of 21 and 35 years: (A) current IDUs from the last 12 months, and (B) other youth regardless of their drug use (current non-IDUs). Survey data collection began in December 2003 and ended in December 2004. We surveyed 240 non-IDUs and 63 current IDUs.

Before the recruitment was carried out, we conducted ethnographic studies of the neighbourhoods to know the place where IDUs live and hang out. Outreach workers who knew local IDUs from prior projects later used targeted sampling and snowball sampling to identify and recruit IDUs. After young IDUs were interviewed, we recruited non-IDUs who lived nearby, or hung around in the localities where IDUs were recruited. Work occurred between 10 am and $6 \mathrm{pm}$ to ensure better security conditions for the working team.

We used a variety of methods to recruit non-IDU youth. We recruited equal numbers ( $65-70)$ by each of the following three methods: (A) quota-samples from door-to-door recruitment near the houses where IDUs lived or hung out; (B) street-intercept methods in these same places using randomized times to avoid biases based on time of day and (C) respondent-assisted network recruitment of non-IDU participants' friends.

Additional ethnographic methods used in the research included nine key informant interviews of IDUs and non-IDUs, elder members of the community, and workers from a local community health care centre; two focus groups with male non-IDUs, and two focus groups with male IDUs and former IDUs. Field observations also took place from 2003 to 2004 .

Participants in the survey and the ethnography signed informed consents after the project procedures were explained to them. International and national ethical guidelines for biomedical research involving human subjects were strictly followed (CIOMS, 2002). Confidentiality was maintained through the assignment of code numbers to all interviewees and other materials containing information of the participants. All data were carefully stored. All procedures were approved by the Institutional Review Boards of Fundación Huésped in Buenos Aires and of National Development and Research Institutes, Inc., New York. Participants were reimbursed for their time and effort with a voucher they could exchange for food at local supermarkets.

\section{Questionnaire}

Measures of drug use. Questions on drug use asked what type of drug (cannabis, non-prescription medicines, solvents and cocaine) the participants had used. We also asked about the method of consumption (smoked, inhaled and injected); the participants' age when they first used each drug; when they last time consumed it and their frequency of use in their life, in the last 12 months and in the last month.

We adapted the Flom et al. (2001a, b, c) hierarchical drug use risk scale to Argentine conditions. We utilized four hierarchical categories that describe the 
participant's drug use in the last 12 months: (1) did not use drugs; (2) used cannabis/non-prescription medicines/solvents; (3) used non-injected cocaine (NI cocaine) and (4) injecting drug use.

If a participant consumed more than one type of substance, the categories utilized for the analysis were exclusive. If someone consumed more than one substance, they were placed in the category of highest risk; for example, current IDUs are included in the category injecting drug use even if they inhaled cocaine or smoked cannabis; and among non-IDUs, those who consumed cocaine were included in the category NI cocaine even though they also smoked cannabis.

\section{Measuring sexual risk}

Variables to describe sexual risk focused on sex with the opposite sex. We asked about: (1) number of opposite-sex partners (heterosexual) in the last three months; and (2) about the proportion of those times they used a condom in the last three months. Condom use answer categories none, very little/very few, less than a half, about half, more than half, almost all, all were collapsed for analysis into 'None' (none), 'sometimes' (very little/very few, less than a half, about half, more than half, almost all) and 'All' (all).

\section{Measuring norms}

External norms were operationalized in two ways:

1. Questions about the number of friends who had encouraged the participant to use injectable drugs or who had encouraged her/him to have sex with IDUs. These questions attempted to elicit actual events in which participants were subjected to normative influence.

2. Questions about the number of friends the participant thought would object if the participant were to engage in such behaviours. These questions attempted to elicit anticipated external normative influence as a potential deterrent force.

The wording of the questions was as follows (though, of course, in Spanish):

1. What proportion of your close friends/associates encourage you to inject drugs?

2. Have any of your close friends/associates ever encouraged you to have sex with someone they thought injected drugs?

3. What proportion of your close friends/associates would object if you injected drugs?

4. What proportion of your close friends/associates would object if you had sex with someone who injects drugs?

Possible answers for questions 1, 3 and 4 were: none, very few, less than half, about half, more than half, almost all and all. These categories were collapsed in analysis so that for question 1 the categories were 'None' (none) and 'At least one' (very ferw, less than half, about half, more than half, almost all and all); and for 3 and 4 
the categories were 'All' (all) and 'Not all' (none, very few, less than half, about half, more than half, almost al). In question 2, the response was Yes or No.

Internalized norms were elicited with questions about the interviewee's opinions of others' behaviours:

1. How do you feel about people who have sex with drug injectors?

2. How do you feel about people who distance themselves from someone because they find out he/she is a drug injector?

The possible answers for both questions were: Think more of them, Not change my opinion of them, Think less of them.

\section{Statistics}

For cross tabs with ordinal variables we used Kendall's $\tau_{C}$ statistic. To compare means, we used the non-parametric Kruskal-Wallis and Mann-Whitney tests for ordinal categories and Chi-squared for nominal variables.

\section{Results}

Sample description

Of the 303 participants, $55 \%$ were male and $45 \%$ female; and $86 \%$ of the IDUs were men. Ages ranged from 21 to 35 years, with a mean age of 27.2 years. Most of the (59\%) participants had a stable sex partner, and $47 \%$ had children. Sixtynine percent of the total participants had graduated from primary school, but only $22 \%$ had graduated from high school. An additional 4 non-IDUs had obtained university degrees. Of the 303 participants interviewed, 65\% responded that they did not work (in paid employment) (Table I).

The majority of the interviewees reported that their monthly income did not fulfil the standards required to satisfy basic needs. The poverty line according to Argentina's National Centre of Statistics and Census for 2004 was 700 pesos ( 1 US dollar $=3$ pesos), but $50 \%$ of the respondents ( 151 people) earned between 100 and 300 pesos each month; 19\% (56) earned between 300 and 500 pesos and $14 \%$ (42) earned less than 100 pesos. An important consideration, however, is the fact that not all the polled persons were the primary wage earners of the household. Incomes are similar between IDUs and non-IDUs, and between men and women.

\section{Drug use}

More than half of the interviewees had not used drugs in the last 12 months $(53.5 \%)$. As primary substances, $11.5 \%$ used cannabis/non-prescription medicines/solvents and the use of NI cocaine was $14.2 \%$. Injectable drug use accounted for $20.8 \%\left(\chi^{2}=58.06, p<0.001\right)$ (Table I). 
Table I. Sample description.

\begin{tabular}{|c|c|c|c|c|c|c|c|}
\hline & \multicolumn{7}{|c|}{ Kendall's } \\
\hline & Total & Men & Women & $\tau_{C}$ & $p$-Value & Chi-square & $p$-Value \\
\hline$N$ & 303 & 168 & 135 & & & & \\
\hline Total & $100 \%$ & $55.4 \%$ & $44.6 \%$ & & & & \\
\hline \multicolumn{8}{|l|}{ Age } \\
\hline \multirow[t]{2}{*}{$21-25$} & 115 & 63 & 52 & 0.021 & 0.733 & 1.294 & 0.524 \\
\hline & $38 \%$ & $37.5 \%$ & $38.5 \%$ & & & & \\
\hline \multirow{2}{*}{$26-30$} & 97 & 58 & 39 & & & & \\
\hline & $32 \%$ & $34.5 \%$ & $28.9 \%$ & & & & \\
\hline \multirow[t]{2}{*}{$31-35$} & 91 & 47 & 44 & & & & \\
\hline & $30 \%$ & $28.0 \%$ & $32.6 \%$ & & & & \\
\hline \multicolumn{8}{|l|}{ Have stable sex partner } \\
\hline No & $\begin{array}{l}123 \\
40.6 \%\end{array}$ & $\begin{array}{l}73 \\
43.5 \%\end{array}$ & $\begin{array}{r}50 \\
37 \%\end{array}$ & 0.063 & 0.256 & 1.277 & 0.156 \\
\hline Yes & $\begin{array}{l}180 \\
59.4 \%\end{array}$ & $\begin{array}{l}95 \\
56.5 \%\end{array}$ & $\begin{array}{r}85 \\
63 \%\end{array}$ & & & & \\
\hline \multicolumn{8}{|l|}{ Have children } \\
\hline No & $\begin{array}{l}162 \\
53.5 \%\end{array}$ & $\begin{array}{l}108 \\
64.3 \%\end{array}$ & $\begin{array}{r}54 \\
40 \%\end{array}$ & 0.240 & 0.000 & 17.744 & 0.000 \\
\hline Yes & $\begin{array}{l}141 \\
46.5 \%\end{array}$ & $\begin{array}{l}60 \\
35.7 \%\end{array}$ & $\begin{array}{r}81 \\
60 \%\end{array}$ & & & & \\
\hline \multicolumn{8}{|l|}{ Education } \\
\hline None & $\begin{array}{l}24 \\
7.9 \%\end{array}$ & $\begin{array}{l}14 \\
8.3 \%\end{array}$ & $\begin{array}{l}10 \\
7.4 \%\end{array}$ & 0.131 & 0.015 & 10.206 & 0.017 \\
\hline Primary & $\begin{array}{r}209 \\
69 \%\end{array}$ & $\begin{array}{l}125 \\
74.4 \%\end{array}$ & $\begin{array}{l}84 \\
62.2 \%\end{array}$ & & & & \\
\hline Secondary & $\begin{array}{l}66 \\
21.8 \%\end{array}$ & $\begin{array}{l}29 \\
17.3 \%\end{array}$ & $\begin{array}{l}37 \\
27.4 \%\end{array}$ & & & & \\
\hline University & 4 & - & $\begin{array}{r}4 \\
3 \%\end{array}$ & & & & \\
\hline \multicolumn{8}{|l|}{ Have work } \\
\hline No & $\begin{array}{r}197 \\
65 \%\end{array}$ & $\begin{array}{l}104 \\
61.9 \%\end{array}$ & $\begin{array}{l}93 \\
68.9 \%\end{array}$ & -0.69 & 0.202 & 1.605 & 0.126 \\
\hline Yes & $\begin{array}{r}106 \\
35 \%\end{array}$ & $\begin{array}{l}64 \\
38.1 \%\end{array}$ & $\begin{array}{l}42 \\
31.1 \%\end{array}$ & & & & \\
\hline \multicolumn{8}{|l|}{ Drug use in last 12 months } \\
\hline Didn't use drug & $\begin{array}{l}162 \\
53.5 \%\end{array}$ & $\begin{array}{l}58 \\
34.5 \%\end{array}$ & $\begin{array}{r}104 \\
77 \%\end{array}$ & -0.457 & 0.000 & 58.059 & 0.000 \\
\hline \multirow{2}{*}{$\begin{array}{l}\text { Cannabis/Non-prescription } \\
\text { medicines/Solvents } \\
\text { Non-injected cocaine }\end{array}$} & $\begin{array}{l}35 \\
11.5 \%\end{array}$ & $\begin{array}{l}23 \\
13.7 \%\end{array}$ & $\begin{array}{l}12 \\
8.9 \%\end{array}$ & & & & \\
\hline & $\begin{array}{l}43 \\
14.2 \%\end{array}$ & $\begin{array}{l}33 \\
19.6 \%\end{array}$ & $\begin{array}{l}10 \\
7.4 \%\end{array}$ & & & & \\
\hline Injecting drugs & $\begin{array}{l}63 \\
20.8 \%\end{array}$ & $\begin{array}{l}54 \\
32.2\end{array}$ & $\begin{array}{l}9 \\
6.7 \%\end{array}$ & & & & \\
\hline
\end{tabular}

Women were less likely to report using drugs than men (Table I): $77 \%$ of women had not consumed drugs in the last 12 months as compared to $35 \%$ of men $\left(\chi^{2}=58.06, p<0.001\right)$.

In Argentina, cocaine is the most commonly injected substance. Heroin is very rare. The majority of IDUs surveyed injected cocaine $(98.4 \%$ of $n=63)$. A few 


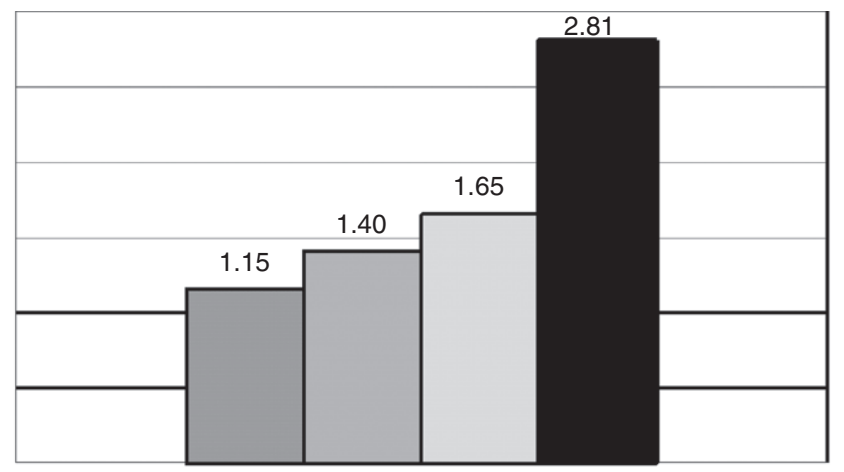

$$
\begin{aligned}
& \square \text { Didn't use ( } N=162) \\
& \square \text { Cannabis/non-prescription medicines/solvents }(\mathrm{N}=35) \\
& \text { - Nl cocaine ( } N=43) \\
& \text { - Injecting drugs ( } N=62 \text { ) } \\
& F=15.681, \mathrm{df}=3 \\
& p \leq 0.001 \text { by ANOVA }
\end{aligned}
$$

Figure 1. Mean number of opposite-sex sex partners by drug use.

had also injected amphetamines (33.3\%), alcohol (20.6\%), ketamine (15.8\%) or morphine $(12.7 \%)$ at least once in their lives.

\section{Hierarchical drug risk scale and sexual risk behaviours}

The association with sexual practices with the risk of transmitting diseases such as HIV/AIDS was analysed to see if the results paralleled those found by Flom et al. (2001b) and, if so, to thereby provide some degree of construct validation for the hierarchical scale for the use of drugs.

Greater risk on the scale of drug use is associated with a greater average number of sex partners (Figure 1): IDUs average 2.81, users of NI cocaine 1.6, cannabis/ non-prescription medicines/solvents users 1.4 and non-users 1.15 (ANOVA, $F=15.681, \mathrm{df}=3, p<0.001$ ). Similarly, pairwise comparisons between drug-use categories found significant differences in mean numbers of partners between those who did not use drugs and NI cocaine users, and between IDUs and each of the other groups (Mann-Whitney test $=1031.5, Z=-2.185, p<0.05$ ). No significant differences were observed between non-users and cannabis/nonprescription medicines/solvents users (Mann-Whitney test $=2478, Z=-1.478$, $p>0.05$ ) or between the latter and NI cocaine users (Mann-Whitney test $=701.5, Z=-0.573, p>0.05)$.

Overall, $25 \%$ of the sample reported that they never used condoms, and $37 \%$ reported they always used them, during the last three months (Table II). There is a significant association between drug use in the last 12 months and condom use in anal and vaginal sex with opposite-sex partners in the last three months $\left(\tau_{C}=-0.115, p=0.018\right)$. Non-users of drugs and users of cannabis, non-prescription medicines or solvents were more likely to use condoms consistently than were IDUs or NI cocaine users. 
Table II. Relationship between risky sexual practices and drug use.

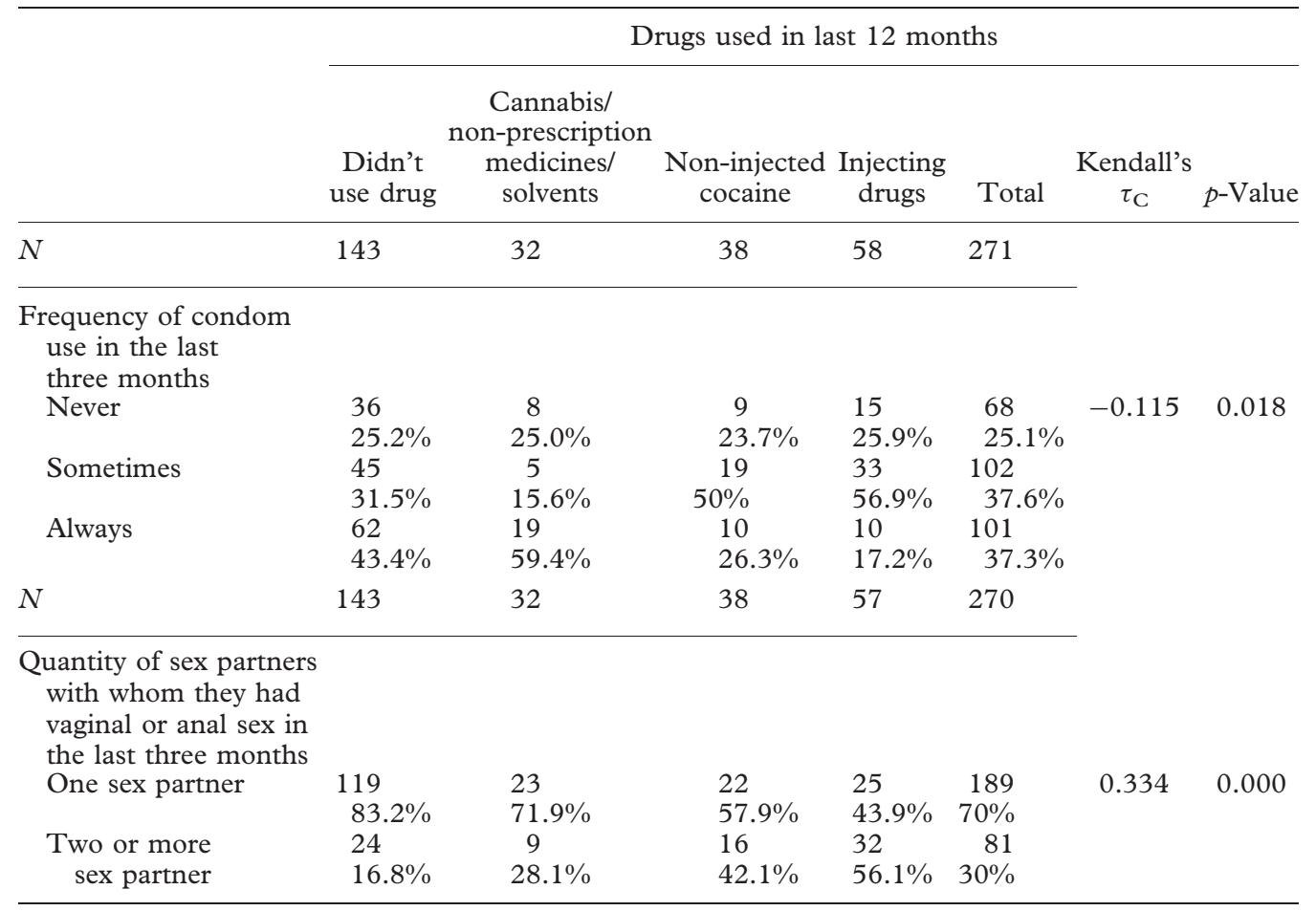

Hierarchical drug use scale and external norms about injecting drugs

In Table III, we can observe the association between external norms and the use of drugs. Of the total surveyed $(n=303)$, very few $(12 \%)$ had any friends who encouraged injection drug use. Furthermore, $71 \%$ reported that all their friends would object to their injecting drugs.

Among IDUs, 38\% had some friends who had encouraged them to inject. Generally, the proportion of participants with some friends who encouraged drug injection was low for other categories in the drug use scale, but was higher for those with riskier drug use across the scale as a whole $\left(\tau_{C}=0.284, p<0.001\right)$ and also among the non-IDU categories $\left(\tau_{C}=0.104, p=0.004\right)$.

Objection to injection drug use was more frequent among those who did not use drugs $(89.2 \%)$, those who used cannabis/non-prescription medicines/solvents $(79.4 \%)$ and NI cocaine $(65.9 \%)$, than with IDUs $(24.6 \%)\left(\tau_{C}=-0.492\right.$, $p<0.001)$. When IDUs were excluded to observe how norms varied within the non-IDUs, this association remained statistically significant $\left(\tau_{C}=-0.164\right.$, $p=0.002)$.

Hierarchical drug use scale and external norms about having sex with IDUs

In general, very few youth had friends who encouraged having sex with IDUs ( $7.9 \%$ of $n=302)$ (Table III). This norm varies by the type of drug consumption 


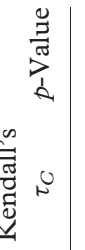

\begin{tabular}{llll}
8 & 8 & 8 & 8 \\
\hdashline & 0 & 0 & 0 \\
0 & 0 & 0 & 0
\end{tabular}

$\frac{5}{0}$

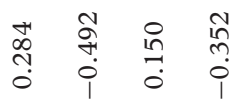

$\stackrel{?}{0}$

ज्ञ

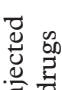
荘

उ্ّ

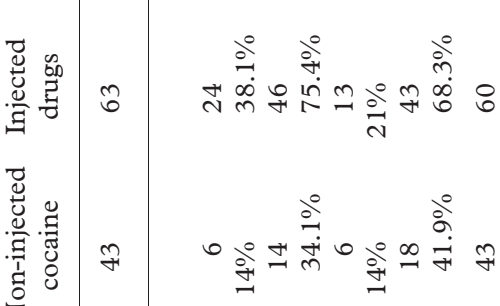
हैं

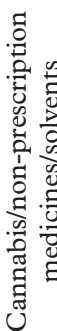

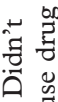

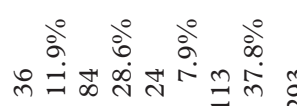

ते

H 离

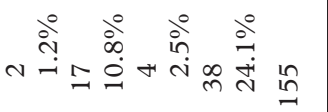

$\stackrel{\infty}{2}$
वें in

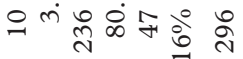

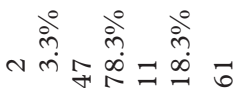

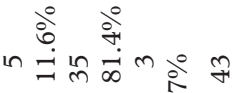

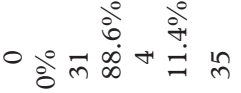

m

ฐ్ี

㟧

घี

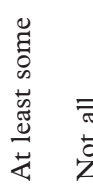

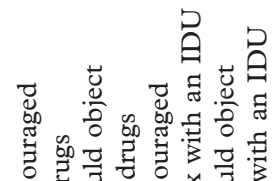

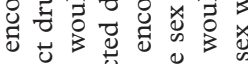

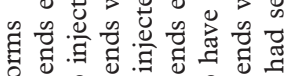

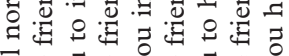

西

造过

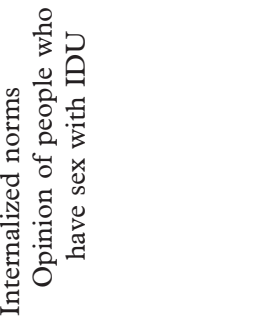

$\stackrel{n}{0}$

$\stackrel{9}{7}$

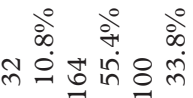

กें ठํ ڤे

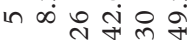

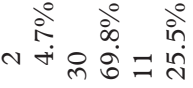

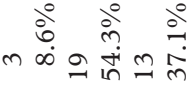

ํำ

삼

छี

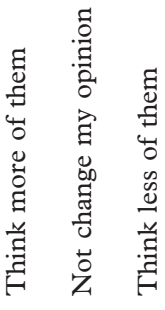

密 若

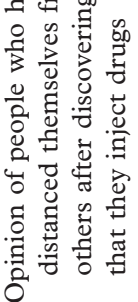


$\left(\tau_{C}=0.150, p<0.001\right)$. Within IDUs encouragement to have sex with IDUs was more frequent, $21 \%$; for the users of NI cocaine, (14\%); those who used cannabis/non-prescription medicines/solvents, $(2.9 \%)$ and those who did not use drugs, $(2.5 \%)$.

Most of the participants (62\%) said that all of their friends would object for having sex with IDUs. This norm also varies by drug use category both among all four categories of drug use $\left(\tau_{C}=-0.352, p<0.001\right)$ and with IDUs excluded $\left(\tau_{C}=-0.152, p=0.011\right)$

\section{Hierarchical drug use scale and internalized norms}

A large majority $(80 \%)$ of the surveyed youth reported that their opinion of someone does not change if he or she has sex with an IDU. Our qualitative records of interviews and focus groups shows that participants used language about this issue such as 'people do what they want' and 'they do their own thing' ('cada uno hace lo que le parece', 'que haga la suya').

There is no significant association between the hierarchical drug use scale and this internalized norm $\left(\tau_{C}=-0.049, p=0.191\right)$ because $18 \%$ of both IDUs and those who did not use drugs reported they would think less of them. However, in post hoc analyses, among the non-IDUs, those lower on the drug hierarchy of risk were more likely to think less of those who have sex with IDUs $\left(\tau_{C}=-0.100, p=0.006\right)$.

Only $11 \%$ of the participants reported that they have a better opinion of people who distance themselves from somebody who is an IDU; and $34 \%$ have a worse opinion of those who do this. Overall, more than half of the youth (55\%) say that it does not change their opinion. The association between the norm scale and the hierarchical drug use is statistically significant $\left(\tau_{C}=0.119, p=0.013\right)$, with IDUs being more likely to think less of those who distance themselves from injectors and non-users being more likely to think more of those who distance themselves from IDUs.

\section{Discussion}

Comparisons with findings from the Flom et al. papers

The design and resources of the project underlying the Flom et al. papers allowed considerable validation of the measures of external norms as well as construct validation of the hierarchical drug risk scale. The external norms in the New York study were validated by comparisons with retrospectively reported external norms when participants were 15 years old, as well as by comparison with the current behaviours of participants and of their friends (Flom et al., 2001a, c).

Although the categories in the hierarchical drug risk scale in the New York study differed from those used here due to the rarity of heroin use and the lack of a 'crack epidemic' in Buenos Aires, higher risk on their drug use scale was also associated with greater numbers of sex partners as well as with greater unprotected sex and with other measures of sexual risk (Flom et al., 2001b). 
The similar findings of the two studies provide a degree of construct validation for the measures used in both studies, and also suggest that norms and behaviours have similar associations in the two localities.

\section{Summary}

The methods used to measure hierarchical drug use risk and peer norms, developed by Flom et al. (2001a) in the New York study, proved useful for our study in Buenos Aires of how drug use is associated with sexual risk and with external and internalized norms about drug injection and having sex with IDUs.

The hierarchical scale of drug use behaviours was, as expected, associated with sexually risky practices. The risk was greater for injecting drug users and NI cocaine than for those who did not use drugs or used cannabis/non-prescription medicines/solvents in the last 12 months.

The hierarchical drug risk scale was also associated with external norms in the anticipated directions, and also with one of the internalized norms (distancing oneself from IDUs). On the other internalized norm, the association held within the non-IDU subset, but IDUs were unexpectedly likely to think less of those who had sex with IDUs.

\section{Limitations of this study}

The major limitation of this study is that there was no independent confirmation of the peer norms since peers were not themselves asked about what they had said to respondents. Another limitation is that data on drug use and sexual behaviours relied on self-report. This may have led to underreporting of stigmatized behaviours (Des Jarlais et al., 1999; Metzger et al., 2000; Newman et al., 2002; Perlis, Des Jarlais, Friedman, Arasteh, \& Turner, 2004; Simões Bastos, Moreira, Lynch, \& Metzger, 2006) and perhaps, if this underreporting is correlated with the measures of external norms, to errors in the measured associations between norms and behaviours.

Since this was not a probability sample (due to the needs of the broader study of which this article is a part), caution must be exercised in interpreting $p$-values for associations and in interpreting the extent to which findings can be generalized beyond the sample. Since drug use is a highly-stigmatized set of behaviours, it is impossible to create random samples of drug users. Nonetheless, considerable knowledge has been acquired through non-random community samples in studies of drug users and their neighbourhoods by us (Friedman et al., 1989, 2004, 2007a, b, 2008; Neaigus, Miller, Friedman, \& Des Jarlais, in press; Rossi et al., 2008) and others (Andia, Deren, Robles, Kang, \& Colon, 2008; Latkin, Forman, Knowlton, \& Sherman, 2003; Latkin \& Knowlton, 2005).

Finally, in a cross-sectional design that we used, associations should not be interpreted as demonstrating causation. The measures of hierarchical drug risk and of norms, however, can be used in future studies of causation. 


\section{Suggestions for future research and public health policy and programs}

Overall, these results suggest that these scales are useful in two very different cultural environments; and the similarities of findings between this article and those by Flom et al. (2001a, b, c) suggest, within the limitations discussed above, the possibility that there may be similar patterns of causation at work in these localities as well.

Similar studies in other locations might help to determine geographic and situational limitations to these scales. To the extent that they are validated, they can be used in a wide variety of further research, including longitudinal studies of change and stability in norms and behaviours.

Within the United States, Flom and his colleagues used these external norms and drug risk scales in a later study of risk networks, social patterns, and the distribution of HIV, sexually transmitted infections and hepatitis virus infections (Friedman et al., 2004, 2005, 2007a, c). Other researchers have either adapted these external norms scales (Andia et al., 2008) or used very similar measures in cross-sectional studies. Andia et al. found that encouragement to share paraphernalia other than syringes was associated among New York City drug injectors with indirect sharing. Steinman (2005) found that, among high school students in a US metropolitan area, friends' and adults' support for substance use was associated with selling drugs. Gyarmathy and Latkin (2008) found that injecting and non-injecting drug users who had friends who encouraged treatment were more likely to enter both the 12-step programs and the methadone programs than other drug users. Future work in the United States or Argentina might test whether these measures of external norms are associated with subsequent behaviour change. If they are, then this would increase the construct validation of these scales. Similarly, the external norms measures can be used in prevention trials aimed at changing normative pressures so as to decrease the risk behaviours.

These measures of norms focus on external norms, and thus on external social relationships and their associations with behaviours. This can be distinguished from measures of internalized norms such as internalized values or beliefs about what is proper. Specifically, our measures consider both recalled events in which others urged the participant to engage in a behaviour and also the (internalized) expectation of (external) sanctions by others if the participant engages in this behaviour. As a consequence, the external norm scales let researchers study how interventions, changes in communities, or changes in living circumstances affect the normative pressures to which participants are subjected in their daily lives.

One issue of considerable interest is how external norms affect internalized norms, and how together these affect behaviours. One useful way of looking at these relationships as part of larger processes is that drug users and others in their communities produce or maintain external norms in the course of intervention_and that these external norms may then affect both internalized norms and behaviours (Friedman et al., 2004, 2005, 2007a). Longitudinal study of these processes using the scales studied in this article might help us to understand the processes and forces that lead to behaviour change. 
Thus, these scales can be used in research on the social, economic, political and other variables that influence norms in their neighbourhood and social network contexts. Because these norms appear to be highly related to drug use, and because drug use is a major public health problem, policies or other forces which affect these norms (intentionally or unintentionally) may have substantial effects on public health.

One such specific and important area is research on the consequences of 'Big Events' such as wars and political-economic transitions, which have on some occasions led to widespread increases in drug use and in related infectious diseases such as HIV and hepatitis C (Friedman et al., 2008). In this research, ways to measure external norms, and the hierarchical risk scale of drug behaviours, can help us understand how the 'Big Event' and related autonomous action by neighbourhood residents, especially teenagers and drug users, affects normative regulation, youth alienation, networks, external norms and drug behaviours.

The findings of such research can then help in the design of programs or interventions that aim to change the peer norms of young people and others so as to reduce harmful drug use.

\section{Acknowledgments}

We deeply thank Paula Goltzman, Gustavo López Arrojo, Mónica Gustas and Viviana Vásquez for their important contributions to data collection, we also appreciate the collaboration of Dante Furioso for his language assistance, Sabrina Dominguez for editing the article and all the volunteers for participating in this study. The authors would also like to acknowledge support from US National Institute on Drug Abuse project R01 DA13128 (Networks, Norms, and HIV/STI Risk among Youth) and its supplement (Networks, Norms \& Risk in Argentina's Social Turmoil). Additional support was provided by Fogarty International Center/NIH grant through the AIDS International Training and Research Program at Mount Sinai School of Medicine-Argentina Program (Grant \# D43 TW001037).

Declaration of interest: The authors report no conflicts of interest. The authors alone are responsible for the content and writing of the paper.

\section{References}

Andia, J. F., Deren, S., Robles, R. R., Kang, S. Y., \& Colon, H. M. (2008). Peer norms and sharing of injection paraphernalia among Puerto Rican injection drug users in New York and Puerto Rico. AIDS Education E Prevention, 20, 249-257.

CIOMS (2002): International ethical guidelines for biomedical research involving human subjects. Geneva: Council for International Organizations of Medical Sciences/WHO, 2002. Available at: http://www.cioms.ch/frame_guidelines_nov_2002.htm. Accessed March 27, 2003. 
Des Jarlais, D. C., Paone, D., Milliken, J., Turner, C. F., Miller, H., Gribble, J., Shi, Q., Hagan, H., \& Friedman, S. R. (1999). Audio-computer interviewing to measure risk behavior for HIV among injecting drug users: A quasi-randomized trial. Lancet, 353(9165), 1657-1661.

Flom, P. L., Friedman, S. R., Benny, J., \& Curtis, R. (2001a). Peer norms regarding drug use and drug selling among household youth in a low-income 'drug supermarket' urban neighbourhood. DRUGS: Education, Prevention and Policy, 8(3), 219-232.

Flom, P. L., Friedman, S. R., Kottiri, B. J., Neaigus, A., Curtis, R., Des Jarlais, D. C., Sandoval, M., \& Zenilman, J. M. (2001b). Stigmatized drug use, sexual partner concurrency, and other sexual risk network and behavioural characteristics of 18-24 year old youth in a high-risk neighbourhood. Sexually Transmitted Diseases, 28, 598-607.

Flom, P.L., Friedman, S. R., Jose, B., Neaigus, A., \& Curtis, R. (2001c). Recalled adolescent peer norms towards drug use in young adulthood in a low-income, minority urban neighbourhood. fournal of Drug Issues, 31, 425-443.

Friedman, S. R., Des Jarlais, D. C., Neaigus, A., Abdul-Quader, A., Sotheran, J. L., Sufian, M., et al. (1989). AIDS and the new drug injector. Nature, 339, 333-334.

Friedman, S. R., Maslow, C., Bolyard, M., Sandoval, M., Mateu-Gelabert, P., \& Neaigus, A. (2004). Urging others to be healthy: 'Intravention' by injection drug users as a community prevention goal. AIDS Education and Prevention, 16, 250-263.

Friedman, S. R., Bolyard, M., Maslow, C., Mateu-Gelabert, P., \& Sandoval, M. (2005). Networks, risk-reduction communication, and norms. Focus, 20;1(January), 5-6.

Friedman, S. R., Bolyard, M., Mateu-Gelabert, P., Goltzman, P., Pawlowicz, M. P., Zunino Singh, D., et al. (2007a). Some data-driven reflections on priorities in AIDS network research. AIDS and Behaviour, 11(5), 641-651.

Friedman, S. R., Bolyard, M., Maslow, C., Mateu-Gelabert, P., Sandoval, M., Ritvo, P., \& Zenilman, J. (2007b). Dificultades potenciales en la implementación a nivel comunitario de la vacunación contra el HIV: Lecciones de la vacunación contra la hepatitis B. Actualizaciones en $\operatorname{SIDA}, 15,139-147$.

Friedman, S.R.; Mateu-Gelabert, P.; Curtis, R.; Maslow, C.; Bolyard, M.; Sandoval, M.; Flom, P.L. (2007c). Social capital or networks, negotiations and norms? A neighborhood case study. American fournal of Preventive Medicine 32(6S):S160-S170). Available at: http://www.pubmed central.nih.gov/articlerender.fcgi?artid $=1995560$

Friedman, S. R., Rossi, D., \& Braine, N. (2008). Theorizing 'Big Events' as a potential risk environment for drug use, drug-related harm and HIV epidemic outbreaks. International fournal of Drug Policy, 20(3), 283-291.

Friedman, S. R., Bolyard, M., Sandoval, M., Mateu-Gelabert, P., Maslow, C., \& Zenilman, J. M. (2008). The relative prevalence of different STIs in HIV-discordant sexual partnerships: Data from a risk network study in a high-risk New York neighborhood. Sexually Transmitted Infections, $84(1), 17-8$.

Gorman, D. M., \& White, H. R. (1995). You can choose your friends, but do they choose your crime? Implications of differential association theories for crime prevention policy. In H. D. Barlow (Ed.), Crime and public policy: putting theory to work (pp. 131-155). Boulder, CO: Westview Press.

Gyamarthy, V. A., \& Latkin, C. A. (2008). Individual and social factors associated with participation in treatment programs for drug users. Substance Use E Misuse, 43, 1865-1881.

Heckathorn, D. D. (1990). Collective sanctions and compliance norms: A formal theory of group-mediated social control. American Sociological Reviews, 55, 366-384.

INDEC (Argentina's National Center of Statistics and Census) (2008) based in the Household Surveys of Buenos Aires (EPH).

Latkin, C. A., Forman, V., Knowlton, A., \& Sherman, S. (2003). Norms, social networks, and HIV-related risk behaviors among urban disadvantaged drug users. Social Science and Medicine, 56(3), 465-76.

Latkin, C. A., \& Knowlton, A. R. (2005). Micro-social structural approaches to HIV prevention: A social ecological perspective. AIDS Care, 17(Supplement 1), S102-S113. 
Mateu-Gelabert, P., Friedman, S. R., \& Sandoval, M. (2007). Pincharse sin infectarse: Estrategias para prevenir la infección de VIH y VHC entre inyectores. Trastornos Adictivos, 9(4), 260-8.

Mateu-Gelabert, P., Bolyard, M., Maslow, C., Sandoval, M., Flom, P. L., \& Friedman, S. R. (2008). For the common good: A method to measure residents' efforts to protect their community from drug and sex related harm. SAHARA fournal, 5, 144-157.

Metzger, D. S., Koblin, B., Turner, C., Navaline, H., Valenti, F., Holte, S., Gross, M., Sheon, A., Miller, H., Cooley, P., \& Seage 3rd, G.R. (2000). Randomized controlled trial of audio computer-assisted self-interviewing: Utility and acceptability in longitudinal studies. HIVNET Vaccine Preparedness Study Protocol Team. American fournal of Epidemiology, 152(2), 99-106.

Neaigus, A., Miller, M., Friedman, S. R., \& Des Jarlais, D. C. (2001). Sexual Transmission Risk Among Non-Injecting Heroin Users Infected with HIV or Hepatitis C. The fournal of Infectious Diseases, 184(3), 359-63.

Newman, J. C., Des Jarlais, D. C., Turner, C. F., Gribble, J., Cooley, P., \& Paone, D. (2002). The differential effects of face-to-face and computer interview modes. American fournal of Public Health, 92(2), 294-297.

Parsons, T. (1951). The Social System. New York: Free Press.

Perlis, T. E., Des Jarlais, D. C., Friedman, S. R., Arasteh, K., \& Turner, C. F. (2004). Audio-computerized self-interviewing versus face-to-face interviewing for research data collection at drug abuse treatment programs. Addiction, 99(7), 885-896.

Rossi, D., Radulich, G., Muzzio, E., Naveira, J., Sosa-Estani, S., Rey, J., Griemberg, G., Friedman, S. R., Martínez Peralta, L., \& Weissenbacher, M. (2008). Multiple infections and associated risk factors among non-injecting cocaine users in Argentina Cad. Saúde Pública, 24(5), 965-974.

Simões, A. A., Bastos, F. I., Moreira, R. I., Lynch, K. G., \& Metzger, D. S. (2006). Acceptability of audio computer-assisted self-interview (ACASI) among substance abusers seeking treatment in Rio de Janeiro, Brazil. Drug and Alcohol Dependence, 82(Supplement1), S103-S107.

Steinman, K. (2005). Drug selling among high school students: Related risk behaviors and psychosocial characteristics. Fournal of Adolescent Health, 36, 71.e71-71.e78. 